\title{
Factors and Influences Contributing to the College/University Selection: A Study of Private Higher Education Institutes (HEIs) in Oman
}

\author{
Niraj Mishra ${ }^{1}$, S.L Gupta ${ }^{2}$ \\ ${ }^{1}$ Department of Management, Birla Institute of Technology International Centre \\ (Waljat College of Applied Sciences) Muscat, Sultanate of Oman \\ ${ }^{2}$ Birla Institute of Technology International Centre, \\ (Waljat College of Applied Sciences) Muscat, Sultanate of Oman
}

\begin{abstract}
HEI selection is an important decision for all aspiring students of higher education and it affects the commitment, motivation to study and career prospects. The present study investigates the factors responsible for student selection of different colleges and universities across Oman. Data has been collected through questionnaire which was both distributed physically and through online mode to students of three private universities and nine private colleges in Oman. The sample size was 300 and consisted of foundation and first year students in diploma and undergraduate courses. The scale items were subjected to reliability and validity checks. Reliability of scale has been tested using "Cronbach alpha", "rho_a" and "composite reliability". The Average Variance Extracted (AVE) was used to test both convergent and discriminant validity of scale. In the present study SmartPLS was used to test the research hypothesis. The relationships between Fixed College Characteristics and HEI selection decision; College Efforts to Communicate and HEI selection decision; Student Characteristics and HEI selection
\end{abstract}

DOI: 10.18421/TEM102-53

https://doi.org/10.18421/TEM102-53

Corresponding author: Niraj Mishra, Assistant Professor, Waljat College of Applied Sciences. Email: nirajmba@gmail.com

Received: 06 January 2021.

Revised: 14 March 2021.

Accepted: 19 March 2021.

Published: 27 May 2021.

(cc) BY-NC-ND (C) 2021 Niraj Mishra \& S.L Gupta; published by UIKTEN. This work is licensed under the Creative Commons Attribution-NonCommercial-NoDerivs 4.0 License.

The article is published with Open Access at www.temjournal.com decision, are found to be significant $(t>1.96$ at $p<$ 0.05). However there is no significant relationship between External Influence and HEI selection decision.

Keywords - Higher Education, College Selection, Private HEIs, PIS, SEM.

\section{Introduction}

Higher education in Oman is growing at a steady pace and is experiencing an increasing competition among the existing universities and colleges across the country and internationally. Oman's higher education consists of 27 private universities and colleges and has an enrollment of 35,000 students. The increasing competition has forced the higher educational institutions (HEIs) to look for areas of competitive advantages and attract students from national and international boundaries. HEI selection is an important decision for all aspiring students of higher education and it affects the commitment, motivation to study and career prospects. A wrong selection may lead to poor motivation, low grades and unemployment situation in the future amongst students. HEIs also need to understand the factors impacting students' choice of university/college which can be utilized for developing marketing strategies to attract aspiring students and having a competitive edge in higher education market in Oman.

The General Framework of the National Strategy for Education 2040 in Sultanate of Oman contains the vision of creating "productive human resources in the world of the knowledge economy with technology networks". In addition, the strategies play a vital role in the implementation of the National Strategy and have a keen aspect of every ratio of society. The strategies have a special focus on student enrollment and building a system which 
provides high quality education to youth as per international standards.

The Oman Vision 2040 also follows a set of general rules and principles to abide by today's challenges and competitive educational systems. The general principles include a new framework for education, in essence, "to identify the body responsible for strategic planning, policy-making, shaping educational law and legislation". Furthermore, capacity building is another principle to implement the strategy successfully, and supervisors for the management of education to achieve improved quality performance and new employment opportunities. Government and Ministry of Higher Education provides scholarship to thousands of students for studying in private HEIs in Oman and abroad. The study will identify the key factors responsible for selection of and HEI by student and thus will help local HEIs to focus on improving their infrastructure and other key aspects which are crucial for decision in HEI selection by students. This will certainly reduce the number of students going outside Oman for Higher Education, and thus will contribute significantly towards the economy of the country. The findings will assist the aspiring students and their parents make an informed decision regarding selection of HEI. This will result in positive commitment, motivation to study, good grades and better career prospects for prospective students. The policy makers and the private HEIs will be able to identify the critical factors responsible for HEI selection by students and take necessary steps to enhance their student admissions.

\section{Literature Review}

A number of studies have been conducted to study the factors responsible for student selection of colleges and universities for higher education [1], [2]. College/university selection has been conceptualized as a three-stage decision process [3]. The first stage speaks about intention of the students to continue their education beyond secondary school. When the students are through the first stage they enter the second stage and start acquiring information about different colleges and their attributes. Students enter the third stage when they get admitted to the college of their choice and start comparing and evaluating their preferred alternatives. Students state that their secondary school education represents the freedom of choice; therefore they can choose and select the college and course.

During early 60 s and 70 s some of the researchers highlighted factors like "academic staff qualifications", "good academic reputation" and "programs" as a key factors influencing student's choice of higher education institutes [4]. Financial aid was found to be a significant factor for selection of HEI. In studies post year 2000 the factors found to be dominating in choice of HEIs were campus location, program, cost, campus size, monetary and non-monetary rewards. Recent studies done in this area has identified cost/benefit, proximity to home, teaching quality, placements, influences from family and friends, facilities of university, financial assistance and etc., as the key factor affecting choice of college/university [5].

\subsection{Location of the College or University}

Chapman called attention to area as one of the generally fixed college attributes that could impact college or university decision since undergraduates want to go to universities that are closer to their houses because of the comfort while the topographical versatility additionally could be influenced by family's salary level as larger part of the college is situated at urban area rather than countryside [6]. Servier has observed that studies have identified location of college or university is one of the most prominent factors affecting decision of prospective students for enrollment [7]. Convenient location, either near home or work place, is mostly sought by prospective students for further their academic pursuit. Hossler \& Gallagher likewise reasoned that the closeness to a college grounds affects college attendance rates [3]. Additionally, an examination by [5] uncovered nearness between the area of college and home is one of the most elevated significance to undergraduates since going to the college close by enable undergraduates to fix better association with family as they ready to expand the recurrence of reaching and visiting their family. A study done on post graduate students in Nigeria also supported that location is an important factors in selection of university [8].

\section{Academic Programmes}

Academic programmes offered by college/university, its scope and adaptability plays a crucial role in enrollment decision by prospective students. [9] found that factors such as "range of programs of study, flexibility of degree program, major change flexibility and range of degree options" are decisive factors is selecting an HEI. An investigation directed in Kuala Lumpur and Selangor, Malaysia by In a study it was additionally found that accessibility of the necessary program as "the very significance characteristics" for the first year college undergraduates to pick a specific college [10]. A study revealed that student admissions in HEIs are mostly affected by extrinsic or institution related factors. The factors that were found to be effective in enhancing student's admissions were 
"current instructional strategy, timely delivery of learning materials and course related information" [11]. Research done in recent past has also revealed that choice of academic programmes offered by colleges / universities influence the choice of prospective students for enrolling at a particular HEI [12], [8], [13].

\subsection{College Reputation}

HEI reputation and image significantly influences the choice of prospective students. As a result, most of the colleges/ universities are going for accreditation which significantly boosts their reputation and image and persuades the prospective students in their searching and selection of HEI. Students prefer the reputation of a college/ university while making their selection decision, [7]. Ismail suggests that the satisfaction level of students with their college choice is high when they make decision on the basis of academic recognition (external influence) [14]. Studies done in this area has echoed similar views and has found that the choice of institution by prospective students is influenced by reputation of the institution. It has also been found that university ranking systems, an effective depiction of reputation and image, influences all stakeholders including prospective students [15]. A recent study has concluded that image and reputation of a college / university image has a positive and significant influence on both "student satisfaction and student loyalty" [16].

\subsection{Costs}

Cost is a key factor for university selection decision by prospective students and almost all students take a note of the total money they will be spending on their education before selecting an HEI. The total cost includes fee, accommodation charges and transportation expenses as there is a vast difference between the fee of a day scholar and boarder. Multiple studies have established the key role of cost in selection of HEI, for example, [12] has examined and established the role of cost on university choice process. Factors responsible for student admission was reviewed by Joseph \& Joseph and it was found that total study cost has gained importance in HEI selection decision with passing years [17]. Foskett has supported the above claims in their study and has concluded that "flexibility of fee payment" and "reasonable accommodation costs" are prominent factors which influence the selection decision of prospective students [18]. Studies done in the area propose that the cost of education has a direct and significant relation with student's intention to study at a university and has also found that the cost is an important factor influencing student choice of college / university [19].

\subsection{Availability of Financial Aid}

An investigation in a study has concluded that money related help offered by college is one of the key factor in college or university selection decision [10]. It has been found in studies that lower income category of youths consider few college alternatives than middle- and upper-income category students. They search for low cost and public higher education institutes as their options. Ismail considered on intervening impact of data on college decision showed that students are happy with college or university decision dependent on their data fulfillment with deferent money related components (external influence) which incorporate monetary guides and moderate expenses [14]. In light of the discoveries referenced previously, it is estimated that accessibility of money related guide has a huge impacted on the college decision choice.

A researcher has stated that accessibility of money related guide applies a critical effect on students' decision of a college or university [18]. It has been seen that financial assistance offered by college/ university is critical in enrollment decision by prospective students. Students who are offered financial aid awards, have a higher probability to take admission in the specific college / university [12]. Studies done recently also have indicated that financial aid is a key factor influencing students' decisions for admission due to soaring costs of higher education [20], [8].

\subsection{Employment Opportunities}

Students opt for post-secondary education since they see it as an essential requirement for career opportunities. It has been established through research that students are influenced by existing job opportunities provided by an HEI, and they are motivated to enroll in a specific college / university based on the existing job status of graduates and their contribution to society [7].

It has been seen that students regularly settle on college decisions depending on the existing employment that open doors for college graduates. Students are keen on results. Studies have established that employment opportunities of graduates represent a key determinant in their college selection decision. A study done in Australia has found that four most important determinants of university preference were "course suitability, academic reputation, job prospects, and teaching quality" [22]. Similar studies were done in Turkey [22] and UK [23] and the outcomes were the same as concluded in earlier studies. "The experiences of adolescents in high school often determine the trajectory of their 
academic preparation, educational expectations, and career knowledge - all of which are critical for achieving postsecondary success" [24]. It has been established empirically that employability of graduates has significant and positive impact on student's choice of higher educational institution [25].

Besides above factors, it has been found in studies that colleges / universities have enhanced their marketing activities through various media platforms in the past few decades. HEIs have been using television and radio advertising to enhance student enrolment by building their reputation, image and visibility across the globe. Younger population is attracted towards social media and marketing activities done through social media has a greater impact on young generation [26]. Effectiveness of Social Media Marketing in Higher Education has been highlighted by several studies done in recent past [27], [28]

\section{Hypotheses and Research Model}

Based on the conceptual foundations developed from the review of literature on factors and influences contributing to the college/university selection the following key factors have been identified as influencers for choosing a specific college/ university. They are: Fixed College Characteristics; Student Characteristics; College Efforts to Communicate and External Influence.

The literature review done in the area has led to identification the following hypotheses for the study:

H1:Fixed College Characteristics is positively related to student's HEI selection decision.

H2: Student Characteristics is positively related to student's HEI selection decision.

H3:College Efforts to Communicate is positively related to student's HEI selection decision.

H4: External Influence is positively related to student's HEI selection decision.

Based on hypotheses mentioned above proposed research model (Figure1) has been framed.

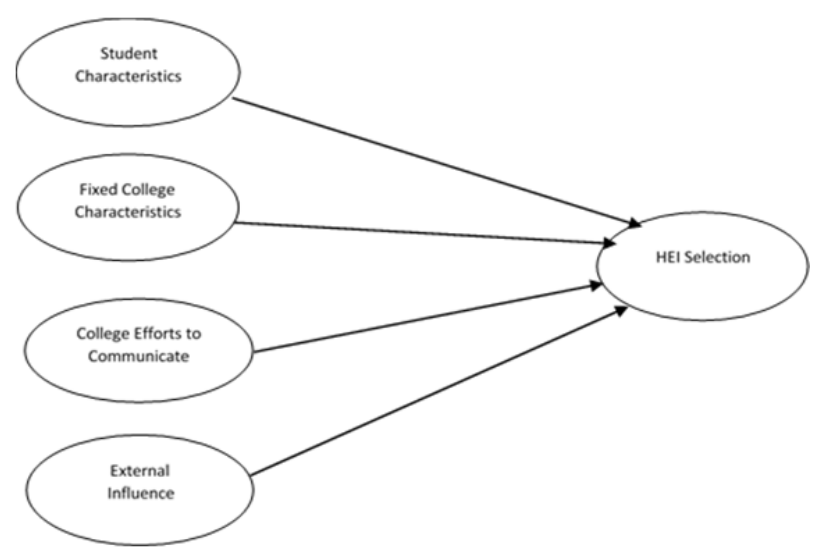

Figure 1. Proposed research model

\section{Methods}

Proposed study is both "exploratory" and "descriptive" in nature. Exploratory research has resulted in exploring the study parameters in detail and understands the concepts and issues related to the study in general. Unstructured and Semi-structured interviews of knowledgeable persons (Experts from regulatory authorities/HEIs) have been done in this regard. Published reports of Ministry of higher education and other agencies have been referred as secondary data. Descriptive research (cross sectional survey) was carried out subsequently through a questionnaire and scale adapted from previous studies to collect primary data from the respondents. Factors which influence preference for particular HEIs were investigated through structured questionnaire. The first part of the questionnaire contains information regarding demographics details (age, gender, course, and nationality) of the respondent. The Second part of the questionnaire focuses on 5 major sections namely: Fixed College Characteristics; Student Characteristics; College Efforts to Communicate; External Influence and HEI selection decision.

The scale items used in questionnaire were adapted from publications having high citations on factors and influences contributing to the college/university selection [12], [28], [29], [5]. The items were modified suitably to fit the context of the study.

The final questionnaire was bi-lingual (English and Arabic) as most of the local students comprehend the questions better in Arabic language. There were 36 measurement items for measuring 5 constructs of the study. The respondents were asked to rate each item on a 5-point Likert scale from $1=$ strongly disagree to $5=$ strongly agree. Questionnaire was both distributed physically and through online mode to students of three private universities and nine private colleges in Oman. The sample size was 300 and consisted of foundation and first year students in diploma and undergraduate courses. Stratified and

purposive sampling methods were appropriately used to have sufficient representation from Omani and expatriate students. Strata were based on: nationality, age, and gender.

The study has used descriptive data analysis for describing the demographic details of respondents. Demographic variables such as age, gender, course, nationality were subjected to basic statistical analysis such as frequency count, mean etc., to understand the demographic details of survey's participants. The scale items were subjected to reliability and validity checks. Reliability of scale has been tested using "Cronbach alpha", "rho_a" and "composite reliability". Average variance extracted (AVE) was 
used to test both convergent and discriminant validity of scale. PLS path modeling has seen wide application recently in business and social sciences and has been used to predict the likely behavior of "endogenous latent variables and to estimate and test relationships between latent variables (causal analysis)" [30]. In the present study SmartPLS was used to test the research hypothesis.

\section{Results and Discussion}

The characteristics of the sample are described in terms of the demographic data provided by the respondents. This data is reported in the order as it appeared in first part of the questionnaire which covered questions relating to the respondents' personal details.

Table 1. Demographic Details of Respondents

\begin{tabular}{|ccc|}
\hline Gender & Frequency & Percent $(\%)$ \\
Male & 88 & 29.3 \\
Female & 212 & 70.7 \\
Age Group & Frequency & Percent $(\%)$ \\
17-19 Years & 88 & 29.3 \\
19-21 Years & 86 & 28.7 \\
21-23 Years & 72 & 24.0 \\
23-25 Years & 12 & 4.0 \\
25-27 Years & 7 & 2.3 \\
27 Years and & 35 & 11.7 \\
Course & Frequency & Percent $(\%)$ \\
Foundation & 89 & 29.7 \\
Diploma & 52 & 17.3 \\
Graduate & 159 & 53.0 \\
Nationality & Frequency & Percent $(\%)$ \\
Omani & 248 & 82.7 \\
Non- Omani & 52 & 17.3 \\
\hline
\end{tabular}

As evident in Table1, there were $29.3 \%$ male respondents and $70.7 \%$ female respondents in the survey. Majority of the respondents were in the age category of 17-19 years (29.3\%) and studying graduate courses $(53 \%)$. Moreover, majority of the respondents were Omani students $(82.7 \%)$.

The constructs of the proposed model were tested for relationship by using the Partial Least Squares (PLS) path-modeling algorithm. SmartPLS has been widely used to predict the measurement model and the structural modeling behavioral sciences [31]. The proposed model is shown in Figure1.The proposed model has five latent constructs as Fixed College Characteristics; Student Characteristics; College Efforts to Communicate; External Influence and HEI selection decision.

SEM analysis requires assessment of measurement model in terms of its "reliability and validity". Reliability has been testing by calculating Cronbach's alpha, rho_a and composite reliability for each of the statements in constructs. rho a is Jöreskog's rhô, generally used for assessing composite reliability in SEM. "Joreskog rhô" is a composite reliability indicator computed on unstandardized loadings where as "Composite reliability" is the same indicator, but it is computed on standardized loadings. This measure is preferred over Cronbach's alpha "because it offers a better estimation of variance shared by the respective indicator" [32]. In this study the Cronbach alpha, rho_a and composite reliability coefficient of the constructs ranged from 0.865 to 0.957 as shown in Table 2 met the standard of 0.70 [33]. Table2 summarizes construct reliability and validity.

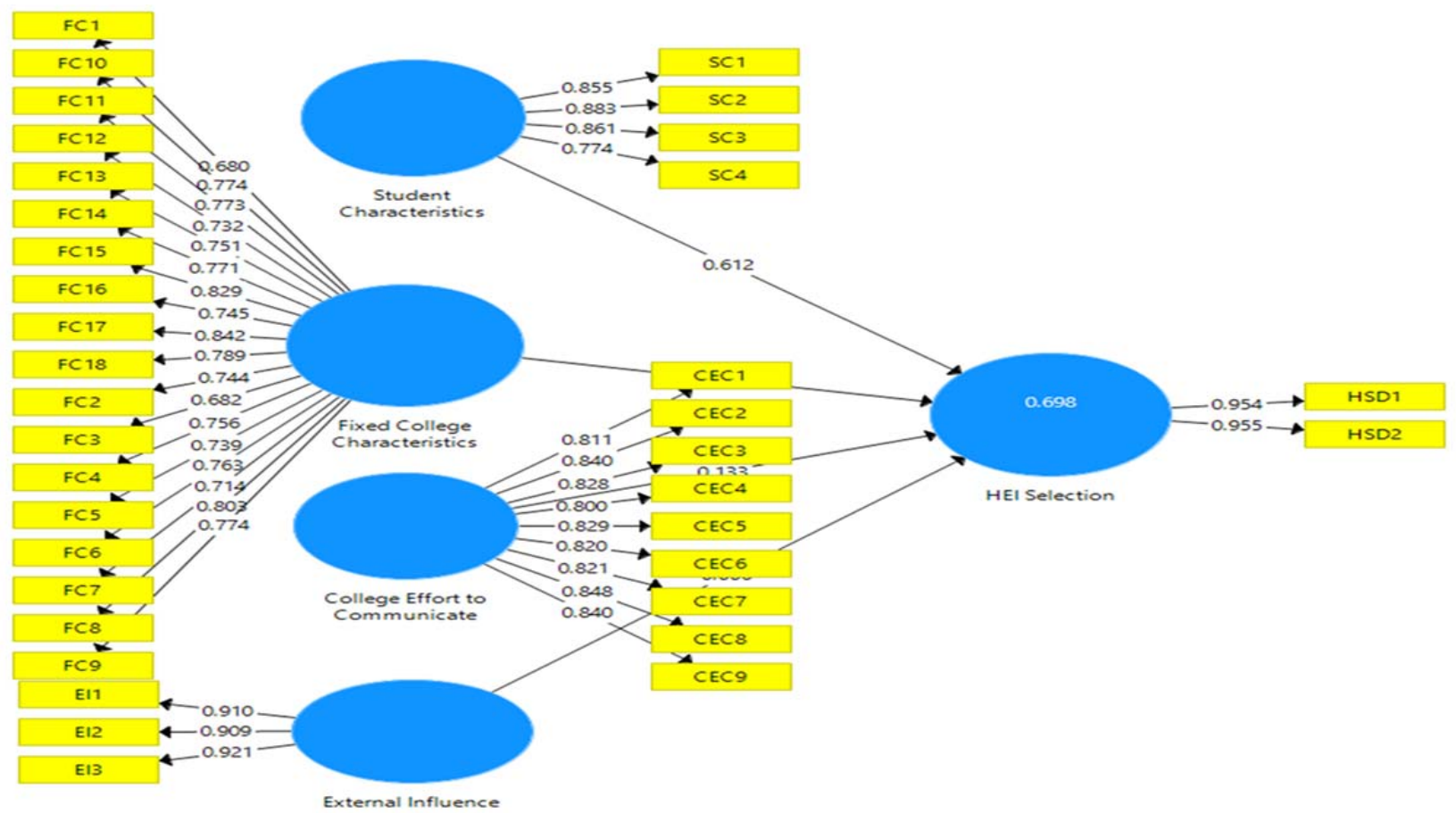

Figure 2. Final path model 
Table 2. Construct Reliability and Validity

\begin{tabular}{||lcccc||}
\hline & $\begin{array}{c}\text { Cronbach's } \\
\text { Alpha }\end{array}$ & rho_A & $\begin{array}{c}\text { Composite } \\
\text { Reliability }\end{array}$ & $\begin{array}{c}\text { Average Variance } \\
\text { Extracted (AVE) }\end{array}$ \\
College Effort to Communicate & 0.942 & 0.942 & 0.951 & 0.683 \\
External Influence & 0.902 & 0.920 & 0.938 & 0.835 \\
Fixed College Characteristics & 0.957 & 0.959 & 0.961 & 0.578 \\
HEI Selection & 0.902 & 0.902 & 0.953 & 0.911 \\
Student Characteristics & 0.865 & 0.873 & 0.908 & 0.713 \\
\hline
\end{tabular}

The measurement models can be evaluated by measuring "internal consistency (composite reliability), indicator reliability, convergent validity (average variance extracted) and discriminant validity" [34]. Factor loading was calculated for the initial path model and is presented in Figure2. As evident from the results all factor loadings were more than 0.7 except for three statements and hence the initial path model was taken as final path model (Figure2). Average variance extracted (AVE) explains how much variance can be measured by a construct with respect to the amount of variance due to measurement error. AVE is also used as a test of both convergent (used to test if the scale items in a construct are closely related) and discriminant validity (how a latent variables discriminates from other latent variables of the study). AVE reflects the average communality for each latent factor in a reflective model. In an adequate model, "AVE should be greater than 0.5. AVE below 0.5 means error variance exceeds explained variance" [21]. As seen in Table3, the AVE scores are above 0.5 and hence is well within the prescribed range.

PLS as a method is used to "maximize variance explained rather than fit and hence predictionoriented measures such as (R2) are used to evaluate PLS models" [21]. The coefficient of determination (R2) is the proportion of the variance in the dependent variable that is predictable from the independent variable. The coefficient of determination is 0.694 for the HEI Selection decision endogenous latent variable. It clearly exhibits that the four latent variables (Fixed College Characteristics; Student Characteristics; College Efforts to Communicate; External Influence) strongly explain $69.4 \%$ of the variance in HEI Selection decision.

Bootstrapping is used in SmartPLS to test the significance of results and path coefficients. A bootstrap procedure using 5000 sub samples was performed in the study to evaluate the statistical significance of path coefficient. The Bootstrap result approximates the normality of data in PLS SEM. The following Table 3 shows hypothesized path coefficient along with their bootstrap values and "T" values.
Table 3. T-Values and P-Values

\begin{tabular}{|c|c|c|c|c|}
\hline & Hyp & T Stat & $P$ Values & Assessment \\
\hline $\begin{array}{l}\text { Fixed College } \\
\text { Characteristics } \\
\text {-> HEI } \\
\text { Selection }\end{array}$ & $H_{1}$ & 4.602 & 0.000 & Supported \\
\hline $\begin{array}{l}\text { Student } \\
\text { Characteristics } \\
\text {-> HEI } \\
\text { Selection }\end{array}$ & $\mathrm{H}_{2}$ & 12.749 & 0.000 & Supported \\
\hline $\begin{array}{l}\text { College Effort } \\
\text { to } \\
\text { Communicate - } \\
>\text { HEI } \\
\text { Selection }\end{array}$ & $\mathrm{H}_{3}$ & 2.848 & 0.004 & Supported \\
\hline $\begin{array}{l}\text { External } \\
\text { Influence -> } \\
\text { HEI Selection }\end{array}$ & $\mathrm{H}_{4}$ & 0.181 & 0.856 & $\begin{array}{c}\text { Not } \\
\text { Supported }\end{array}$ \\
\hline
\end{tabular}

As per the T statistics data exhibited in Table3, the relationships between Fixed College Characteristics and HEI selection decision; College Efforts to Communicate and HEI selection decision; Student Characteristics and HEI selection decision, are found to be significant $(t>1.96$ at $p<0.05)$. However there is no significant relationship between External Influence and HEI selection decision.

\section{Conclusion}

The purpose of this research paper was to investigate the factors and influences contributing to the College/University selection decision of students in private higher education Institutes in Oman. The feedback was collected from 10 private HEIs across Oman and had sufficient representation based on nationality, gender and geographical location. The outcomes revealed that students consider a number of factors critical for HEI selection decision. Factors such as location of the college/university, college /university reputation \& image, academic programs offered, quality of academic staff, accreditation of college / university, employment opportunities by the college /university, foreign university partner, advertising in various media by college / university, career goals and financial capacity were found to be the key factors influencing student choice of HEIs. 
Such factors are not new to studies done in this area but the present study is the one of the few studies done on private higher institutions and particularly the first study in Oman.

It is clear from the study that private HEIs are attracting a lot of students from Oman and other countries. The higher education market in Oman is young and still growing at a rapid pace with new HEIs coming up and offering tailor made courses for meeting the local market requirements. The regulatory authorities in higher education of Oman is striving their best to impart quality education of global standards to students and have made accreditation mandatory for all HEIs. The accreditation exercise has made the HEIs to streamline their processes and focus on quality teaching, learning and research activities.

The study will have direct benefits for the private HEIs and other stakeholders of higher education in Oman. The findings will assist the aspiring students and their parents make an informed decision regarding selection of HEI. This will result in positive commitment, motivation to study, good grades and better career prospects for prospective students. The policy makers and the private HEIs will be able to identify the critical factors responsible for HEI selection by students and take necessary steps to enhance their student admissions

\section{Acknowledgements}

The research leading to these results has received funding from the Research Council (TRC) of the Sultanate of Oman under the Block Funding Program. TRC Block Funding Agreement No. TRC/BFP/WCAS/01/2018

\section{References}

[1]. Haron, H., Hamid, N. A. A., Jamaludin, J., \& Azan, K. N. K. (2017). Students' decision factors in choosing private higher education institutions. International Journal of Academic Research in Business and Social Sciences, 7(11), 1372-1382.

[2]. Akareem, H. S., \& Hossain, S. S. (2016). Determinants of education quality: what makes students' perception different?. Open review of educational research, 3(1), 52-67.

[3]. Hossler, D., \& Gallagher, K. S. (1987). Studying student college choice: A three-phase model and the implications for policymakers. College and university, 62(3), 207-21.

[4]. Baird, L. L. (1967). The educational goals of collegebound youth. ACT Research Reports.

[5]. Ahmad, S. Z., Buchanan, F. R., \& Ahmad, N. (2016). Examination of Students' Selection Criteria for International Education. International Journal of Educational Management, 30(6), 1088-1103.

[6]. Chapman, D. W. (1981). A model of student college choice. The Journal of Higher Education, 52(5), 490505 .
[7]. Sevier, R. A. (1986). Freshmen at competitive liberal arts colleges: a survey of factors influencing institutional choice (Doctoral dissertation, The Ohio State University).

[8]. Adefulu, A., Farinloye, T., \& Mogaji, E. (2020). Factors Influencing Postgraduate Students' University Choice in Nigeria. In Higher Education Marketing in Africa (pp. 187-225). Palgrave Macmillan, Cham.

[9]. John, B. F., Mathew, J., \& Beatriz, J. (1999). Importance-performance analysis as a strategic tool for service marketers: the case of service quality perceptions of business students in New Zealand and the USA. Journal of Services Marketing, 13(2), 171186.

[10]. bin Yusof, M., binti Ahmad, S. N. B., bin Mohamed Tajudin, M., \& Ravindran, R. (2008). A study of factors influencing the selection of a higher education institution. UNITAR e-journal, 4(2), 27-40.

[11]. Rashid, M. M., Jahan, M., Islam, A., \& Ratna, M. M. (2015). Student enrollment and dropout: An evaluation study of DCSA program at Bangladesh Open University. International Review of Research in Open and Distributed Learning, 16(4), 18-32.

[12]. Ming, J. S. K. (2010). Institutional factors influencing students' college choice decision in Malaysia: A conceptual framework. International Journal of Business and Social Science, 1(3).

[13]. Le, T. D., Robinson, L. J., \& Dobele, A. R. (2020). Understanding high school students use of choice factors and word-of-mouth information sources in university selection. Studies in Higher Education, 45(4), 808-818.

[14]. Ismail, N. (2009, June). Mediating effect of information satisfaction on college choice. In A Paper Presented in Oxford Business and Economics Conference Program. UK.

[15]. Taylor, Z. W., Childs, J., Bicak, I., \& Alsmadi, I. (2019). Is bigger, better? Exploring US News graduate education program rankings and internet characteristics. Interchange, 50(2), 205-219.

[16]. Chandra, T., Hafni, L., Chandra, S., Purwati, A. A., \& Chandra, J. (2019). The influence of service quality, university image on student satisfaction and student loyalty. Benchmarking: An International Journal, 26(5), 1533-1549.

[17]. Joseph, M., \& Joseph, B. (1998). Identifying needs of potential students in tertiary education for strategy development. Quality Assurance in Education, 6(2), 90-96.

[18]. Foskett, N., Roberts, D., \& Maringe, F. (2006). Changing fee regimes and their impact on student attitudes to higher education. Southampton: University of Southampton.

[19]. Van Alebeek, W., \& Wilson, K. B. (2019). Explaining the College Choice Decisions of International Students at a Regional University in the United States. Journal of Research in International Education, 18(3), 292-309.

[20]. Festa, M. M., Holderness Jr, D. K., Neidermeyer, A. A., \& Neidermeyer, P. E. (2019). The impact of financial-aid format on students' collegiate financing decisions. Journal of Financial Counseling and Planning, 30(1), 27-43. 
[21]. Chin, W. W. (1998). The partial least squares approach to structural equation modeling. Modern methods for business research, 295(2), 295-336.

[22]. Soutar, G. N., \& Turner, J. P. (2002). Students' preferences for university: A conjoint analysis. International Journal of Educational Management, 16(1), 40-45.

[23]. Veloutsou, C., Lewis, J. W., \& Paton, R. A. (2004). University selection: information requirements and importance. The International Journal of Educational Management, 18(3), 160-171.

[24]. Schneider, B., Broda, M., Judy, J., \& Burkander, K. (2013). Pathways to college and STEM careers: Enhancing the high school experience. New directions for youth development, 2013(140), 9-29.

[25]. Dhaliwal, M. S., Mittal, A., Aggarwal, A., \& Chand, P. K. (2019). Determining the factors affecting the selection of private universities and colleges in indian context: a structural equation modeling approach. Journal of Advanced Research in Dynamical \& Control Systems, 11(8), 2579-2590.

[26]. Duffett, R. G. (2017). Influence of social media marketing communications on young consumers' attitudes. Young Consumers, 18(1), 19-39.

[27]. Almadhoun, N. M., Dominic, P. D. D., \& Woon, L. F. (2011, September). Social media as a promotional tool in higher education in Malaysia. In 2011 National Postgraduate Conference (pp. 1-7). IEEE.
[28]. Lee, P. C., Lee, M. J., \& Dopson, L. R. (2019). Who influences college students' career choices? An empirical study of hospitality management students. Journal of Hospitality \& Tourism Education, 31(2), 74-86.

[29]. Johnston, T. C. (2010). Who and what influences choice of university? Student and university perceptions. American Journal of Business Education (AJBE), 3(10), 15-24.

[30]. Hair, J. F., Ringle, C. M., \& Sarstedt, M. (2011). PLS-SEM: Indeed a silver bullet. Journal of Marketing theory and Practice, 19(2), 139-152.

[31]. Tarka, P. (2018). An overview of structural equation modeling: its beginnings, historical development, usefulness and controversies in the social sciences. Quality \& quantity, 52(1), 313-354.

[32]. Hair Jr, J. F., Sarstedt, M., Hopkins, L., \& Kuppelwieser, V. G. (2014). Partial least squares structural equation modeling (PLS-SEM). European Business Review, 26(2), 106-121.

[33]. Fornell, C., \& Larcker, D. F. (1981). Evaluating structural equation models with unobservable variables and measurement error. Journal of marketing research, 18(1), 39-50.

[34]. Hair, J. F., Risher, J. J., Sarstedt, M., \& Ringle, C. M. (2019). When to use and how to report the results of PLS-SEM. European Business Review, 31(1), 2-24. 